\title{
Two-electron reduction of quinones by Enterobacter cloacae PB2 pentaerythritol tetranitrate reductase: quantitative structure-activity relationships
}

\author{
Lina Misevičienè ${ }^{1}$, Žilvinas Anusevičius ${ }^{1}$, Jonas Šarlauskass ${ }^{1}$, Richard J. Harris², \\ Nigel S. Scrutton ${ }^{2}$ and Narimantas Čènas ${ }^{1 凶}$ \\ ${ }^{1}$ Institute of Biochemistry, Vilnius, Lithuania, ${ }^{2}$ Faculty of Life Sciences, \\ The University of Manchester, Manchester, UK
}

Received: 16 January, 2007; revised: 22 March, 2007; accepted: 27 March, 2007 available on-line: 04 June, 2007

\begin{abstract}
In order to clarify the poorly understood mechanisms of two-electron reduction of quinones by flavoenzymes, we examined the quinone reductase reactions of a member of a structurally distinct old yellow enzyme family, Enterobacter cloacae PB2 pentaerythritol tetranitrate reductase (PETNR). PETNR catalyzes two-electron reduction of quinones according to a 'ping-pong' scheme. A multiparameter analysis shows that the reactivity of quinones increases with an increase in their single-electron reduction potential and $\mathrm{p} K_{\mathrm{a}}$ of their semiquinones (a three-step $\left(\mathrm{e}^{-}, \mathrm{H}^{+}, \mathrm{e}^{-}\right)$hydride transfer scheme), or with an increase in their hydride-transfer potential $\left(E_{7}\left(\mathrm{H}^{-}\right)\right)(\mathrm{a}$ singlestep $\left(\mathrm{H}^{-}\right)$hydride transfer scheme), and decreases with a decrease in their van der Waals volume. However, the $\mathrm{pH}$-dependence of PETNR reactivity is more consistent with a single-step hydride transfer. A comparison of X-ray data of PETNR, mammalian NAD(P)H: quinone oxidoreductase (NQO1), and Enterobacter cloacae nitroreductase, which reduce quinones in a two-electron way, and their reactivity revealed that PETNR is much less reactive, and much less sensitive to the quinone substrate steric effects than NQO1. This may be attributed to the lack of $\pi-\pi$ stacking between quinone and the displaced aromatic amino acid in the active center, e.g., with Phe-178'
\end{abstract} in NQO1.

Keywords: pentaerythritol tetranitrate reductase, quinones, electron-transfer, reduction mechanism

\section{INTRODUCTION}

The therapeutic action and/or toxicity of quinoidal drugs and environmental pollutants is frequently attributed to their flavoenzyme-catalyzed reduction. Single-electron reduction of quinones to their anion-radicals initiates their redox cycling under aerobic conditions, and leads to the oxidative stress ( $\mathrm{O}^{\prime}$ Brien, 1991). Typically, these reactions are performed by flavoenzymes dehydrogenases-electrontransferases, e.g., NADPH:cytochrome P-450 reductase (EC 1.6.4.2) and ferredoxin: $\mathrm{NADP}^{+}$reductase (EC 1.18.1.2), which contain stabilized neutral flavin semiquinones, and possess natural single-electron accepting oxidants (Iyanagi, 1990, and references therein). These reactions follow an 'outer-sphere' electron transfer with a weak electronic interaction between the reactants (Marcus \& Sutin, 1985), and are characterized by a linear or parabolic dependence of log (rate constant) on the single-electron reduction potential of quinones, $E^{1}{ }_{7}$, with an absence of pronounced effects of quinone structure (Čènas et al., 1994; Anusevičius et al., 1997).

${ }^{\square}$ Coresponding author: N. Čènas, Institute of Biochemistry, Mokslininkų 12, LT-08662 Vilnius, Lithuania; e-mail: ncenas@ bchi.lt

Abbreviations: AZQ, 2,5-diaziridinyl-3,6-bis(carboethoxyamino)-1,4-benzoquinone; BZQ, 2,5-bis(2'-hydroxyethylamino)3,6-diaziridinyl-1,4-benzoquinone; $E_{7}^{1}$, single-electron reduction potential at $\mathrm{pH} 7.0 ; E_{7}\left(\mathrm{H}^{-}\right)$, hydride transfer potential at $\mathrm{pH} 7.0 ; K_{\mathrm{ig}}$ quinone substrate inhibition constant; NQO1, NAD(P)H:quinone oxidoreductase; NR, nitroreductase; PETNR, pentaerythritol tetranitrate reductase; $\mathrm{p} K_{\mathrm{a}}(\mathrm{QH}), \mathrm{p} K_{\mathrm{a}}$ of semiquinone; VdWvol, van der Waals volume; . 
Two-electron reduction of quinones frequently contributes to their detoxification, because the relatively stable hydroquinones undergo conjugation, and are readily excreted from organism (O'Brien, 1991, and references therein). However, due to very few mechanistic studies, the mechanism(s) of two-electron (hydride) reduction of quinones by flavoenzymes are unclear, except for the requirement of the instability of anionic flavin semiquinone in the enzyme active center (Tedeschi et al., 1995; Koder et al., 2002, and references therein). In the most thoroughly studied reactions of $\mathrm{NAD}(\mathrm{P}) \mathrm{H}$ :quinone oxidoreductase (NQO1, DT-diaphorase, EC 1.6.99.2) and Enterobacter cloacae nitroreductase (NR, EC 1.6.99.7), the reactivity of quinones in general increases upon an increase in their electron (hydride)-accepting potency, but it is also strongly influenced by their structural peculiarities (Anusevičius et al., 2002; Nivinskas et al., 2002). Thus, it is unclear whether the two-electron reduction of quinones requires their specific interaction(s) with the flavoenzyme active center as well, e.g., the $\pi-\pi$ stacking of quinone with the displaced aromatic amino-acid residue, like Phe-178' in NQO1 (Li et al., 1995). For this reason, it is necessary to extend mechanistic studies of two-electron reduction using flavoenzymes of different groups and families.

Pentaerythritol tetranitrate reductase (PETNR) from E. cloacae strain PB2 is NADPH-oxidizing flavoenzyme containing one noncovalently bound flavin mononucleotide (FMN) per $40 \mathrm{kDa}$ monomer (Binks et al., 1996), and belongs to the structurally distinct old yellow enzyme (OYE) family of flavoenzymes. PETNR possesses broad oxidant specificity, performing the reductive denitration of aliphatic nitroesters such as the explosives pentaerythritol tetranitrate and glycerol trinitrate (Binks et al., 1996), reduction of $\alpha / \beta$ unsaturated compounds such as 2 -cyclohexenone, codeinone, steroids (French et al., 1996; Barna et al., 2001), and nitroaromatic compounds (French et al., 1998; Khan et al., 2002). The midpoint potential of FMN at pH $7.0\left(E_{\mathrm{m}, 7}\right)$ is $-0.267 \mathrm{~V}$ (Khan et al., 2004) with less than $1 \%$ of anionic semiquinone $\left(\mathrm{FMN}^{-}\right.$) stabilized at equilibrium (Khan et al., 2002). There exist some data on the reduction of quinones by OYE (Massey \& Schopfer, 1986), however, their reactions with PETNR have not been studied.

In this study, we have obtained a quantitative structure-activity relationship in the reduction of quinones by PETNR, and distinguished the effects of the electron/hydride-accepting potency of quinones and their steric parameters.

\section{MATERIALS AND METHODS}

E. cloacae PB2 PETNR was purified as described previously (French et al., 1996). The enzyme concentration was determined spectrophotometrically using $\varepsilon_{464}=11.3 \mathrm{mM}^{-1} \mathrm{~cm}^{-1}$. 2-Methyl-3-glutathionyl5-hydroxy-1,4-naphthoquinone and 2,3-diglutathionyl-1,4-naphthoquinone were a generous gift from Dr. K. Ollinger (Linkoping University, Sweden). AZQ (2,5-diaziridinyl-3,6-bis(carboethoxyamino)1,4-benzoquinone) and BZQ (2,5-bis(2'-hydroxyethylamino)-3,6-diaziridinyl-1,4-benzoquinone) were synthesized according to previously described procedures (Chou et al., 1976). All other compounds were obtained from Sigma or Aldrich and used as received.

All the kinetic measurements were carried out in $0.05 \mathrm{M} \mathrm{K}$-phosphate ( $\mathrm{pH} 7.0)$, containing 1 $\mathrm{mM}$ EDTA at $25^{\circ} \mathrm{C}$, using a Hitachi-557 spectrophotometer. The initial rates of PETNR-catalyzed oxidation of NADPH by quinones were determined by monitoring NADPH oxidation $\left(\Delta \varepsilon_{340}=6.2\right.$ $\left.\mathrm{mM}^{-1} \mathrm{~cm}^{-1}\right)$. The kinetic parameters of reactions, i.e., the catalytic constant $\left(k_{\text {cat }}\right)$ and the bimolecular rate constant $\left(k_{\text {cat }} / K_{\mathrm{m}}\right)$ of quinone reduction correspond to the reciprocal intercepts and slopes of the Lineweaver-Burk plots, $[\mathrm{E}] / v$ vs. $1 /[\mathrm{Q}]$, where $v$ is the reaction rate, [E] is the enzyme concentration, and $[\mathrm{Q}]$ is quinone concentration. The $k_{\text {cat }}$ corresponds to the number of molecules of NADPH oxidized by the enzyme active center per second. The quinone substrate inhibition constants $\left(K_{\mathrm{iq}}\right)$ at fixed NADPH concentration were obtained from the intercepts of plots $[\mathrm{E}] / v$ vs. [Q] with the $x$ axis. 1,4-Benzoquinone-mediated reduction of cytochrome $c$ by PETNR was monitored according to $\Delta \varepsilon_{550}=20 \mathrm{mM}^{-1} \mathrm{~cm}^{-1}$ (concentrations of 1,4-benzoquinone and cytochrome $c, 50 \mu \mathrm{M}$, concentration of NADPH, $150 \mu \mathrm{M}$ ).

The quantum chemical calculations of the van der Waals volumes (VdWvol) of quinones were performed using Spartan'04 Pro software (Wavefunction, Inc.). The multiparameter regression analysis was performed using Statistica (version 4.3, Statsoft Inc., 1993).

\section{RESULTS}

Monitoring 1,4-benzoquinone-mediated reduction of cytochrome $c$ by PETNR at $\mathrm{pH}$ 7.0, we found that the rate of cytochrome $c$ reduction was equal to $5 \%$ of the NADPH enzymatic oxidation rate by benzoquinone, determined in the absence of cytochrome $c$. This shows that in the reduction of 1,4benzoquinone single-electron flux constitutes about $2.5 \%$ (the ratio of double cytochrome $c$ reduction rate and NADPH oxidation rate), because 1,4-benzosemiquinone reduces cytochrome $c$ rapidly $\left(k \sim 10^{6}\right.$ $\mathrm{M}^{-1} \mathrm{~s}^{-1}$ ), whereas benzohydroquinone reduces it at a negligible rate at $\mathrm{pH}<7.2$ (Iyanagi, 1990, and refer- 
ences therein). Thus, PETNR reduces quinones in a two-electron way to hydroquinones.

Like in our previous studies of two-electron transferring NQO1 and E. cloacae NR (Anusevičius et al., 2002; Nivinskas et al., 2002), one should consider two possible hydride transfer mechanisms from reduced PETNR $\left(\mathrm{E}-\mathrm{FMNH}^{-}\right)$to quinones. The first is a three-step $\left(\mathrm{e}^{-}, \mathrm{H}^{+}, \mathrm{e}^{-}\right)$mechanism:

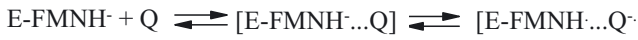

$$
\begin{aligned}
& \left.\longrightarrow \mathrm{E}-\mathrm{FMN}^{-} \ldots \mathrm{QH} \cdot\right] \longrightarrow \mathrm{E}-\mathrm{FMN}+\mathrm{QH}^{-}
\end{aligned}
$$

In this case, quinone reactivity should increase with an increase in their single-electron reduction potential $\left(E_{7}^{1}\right)$ and $\mathrm{p} K_{\mathrm{a}}$ of semiquinone $\left(\mathrm{p} K_{\mathrm{a}}(\mathrm{QH})\right)$ (Fukuzumi et al., 1989). Alternatively, in a singlestep transfer,

E-FMNH + Q $\rightleftarrows\left[\mathrm{E}^{-} \mathrm{FMNH}^{-} \ldots \mathrm{Q}\right] \longrightarrow \mathrm{E}-\mathrm{FMN}+\mathrm{QH}^{-}$

quinone reactivity should increase with an increase in their hydride-transfer potential $\left(\left(E_{7}\left(\mathrm{H}^{-}\right)\right)\right.$, i.e., the potential of the quinone/anionic hydroquinone $(\mathrm{Q} /$ $\mathrm{QH}^{-}$) redox couple (Carlson \& Miller, 1985). The latter is expressed as

$E_{7}\left(\mathrm{H}^{-}\right)=E_{\mathrm{m}, 7}-0.03 \mathrm{~V} \times\left(\mathrm{pK}_{\mathrm{a}}\left(\mathrm{QH}_{2}\right)-7.0\right)$,

where $E_{\mathrm{m}, 7}$ is the midpoint potential of the quinone/ hydroquinone couple at $\mathrm{pH} 7.0$, and $\mathrm{pK} \mathrm{a}_{\mathrm{a}}\left(\mathrm{QH}_{2}\right)$ is $\mathrm{p} K_{\mathrm{a}}$ of hydroquinone. If $\mathrm{p} K_{\mathrm{a}}\left(\mathrm{QH}_{2}\right) \leq 7.0$, then $E_{7}\left(\mathrm{H}^{-}\right)$ $\cong E_{\mathrm{m}, 7}$. We examined the reactivity of PETNR with structurally diverse quinoidal compounds possessing a broad range of $E_{7}^{1}, \mathrm{p} K_{\mathrm{a}}(\mathrm{QH}), E_{7}\left(\mathrm{H}^{-}\right)$, and van der Waals volumes (VdWvol) (Table 1).

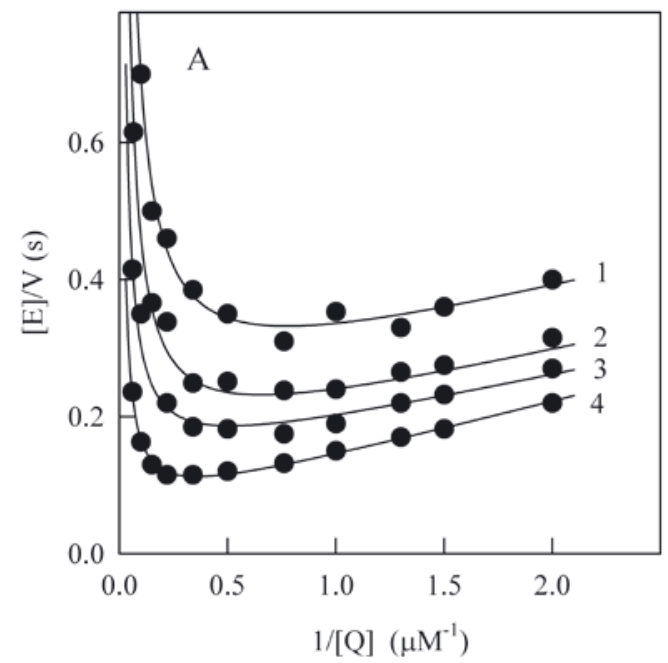

In the reactions of PETNR with 5-hydroxy-1,4napthoquinone (Fig. 1A), 5,8-dihydroxy-1,4-naphthoquinone, 2,6-dimethyl-, trimethyl- and tetramethyl1,4-benzoquinones (not shown), we obtained a series of parallel plots in Lineweaver-Burk coordinates at varied concentrations of quinones and several fixed NADPH concentrations, with an upward curvature at high quinone concentrations. This points to a 'ping-pong' scheme with quinone substrate inhibition. The quinone substrate inhibition constants $\left(K_{\mathrm{iq}}\right)$ increased with an increase in NADPH concentration (Fig. 1B). This shows that quinones bind to the oxidized enzyme form, thus acting as competitive inhibitor towards NADPH. The kinetic parameters of reaction, $k_{\text {cat }}$ and $k_{\text {cat }} / K_{\mathrm{m}}$ for quinone reduction, and $K_{\mathrm{iq}}$ of quinones are given in Table 1 . We were unable to determine $k_{\text {cat }} / K_{\mathrm{m}}$ of 1,4-benzoquinone, because its $K_{\mathrm{m}}$ was below $1.0 \mu \mathrm{M}\left(k_{\text {cat }} \sim 25 \mathrm{~s}^{-1}\right.$ at [NADPH] $=150 \mu \mathrm{M})$. The $k_{\text {cat }} / K_{\mathrm{m}}$ values for NADPH oxidation, determined using several quinone oxidants, did not depend on their nature, being in the range of $4.2 \times 10^{5}-2.9 \times 10^{5} \mathrm{M}^{-1} \mathrm{~s}^{-1}$. The $k_{\text {cat }}$ values for the most active quinones were close to $34 \mathrm{~s}^{-1}$ (Table 1), i.e., close to the maximal rate of the reduction of PETNR by NADPH, determined in the presteadystate kinetics (Basran et al., 2003). Thus, in these cases, the overall reaction rate becomes limited by the reductive half-reaction, and not by the oxidation of reduced PETNR by quinones.

The data of Table 1 show that the reactivity of quinones in general increases with an increase in their electron accepting potency. Analyzing quinone reactivity in terms of a three-step (Eqn. 1) hydride transfer, we found that the linear relationship between $\log k_{\text {cat }} / K_{\mathrm{m}}$ and $E_{7}^{1}$ is poorly expressed

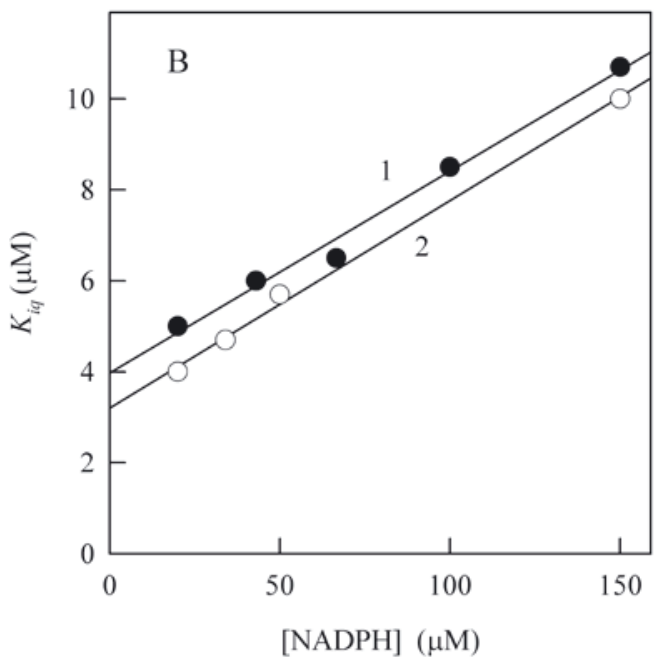

Figure 1. Kinetics of PETNR-catalyzed quinone reduction.

A. The rates of PETNR-catalyzed oxidation of NADPH by various concentrations of 5-hydroxy-1,4-naphthoquinone, presented in Lineweaver-Burk coordinates. Concentration of NADPH, $20 \mu \mathrm{M}(1), 33 \mu \mathrm{M}(2), 50 \mu \mathrm{M}(3)$, and $150 \mu \mathrm{M}(4)$. B. Dependence of the quinone substrate inhibition contants $\left(K_{\mathrm{iq}}\right)$ of 5,8-dihydroxy-1,4-naphthoquinone (1) and 5-hydroxy1,4-naphthoquinone (2) on the concentration of NADPH. 
Table 1. Catalytic $\left(k_{\mathrm{cat}}\right)$ and bimolecular rate constants $\left(k_{\mathrm{cat}} / K_{\mathrm{m}}\right)$ of reduction of quinones by PETNR, their substrate inhibition constants $\left(K_{\mathrm{iq}}\right)$, single-electron reduction potentials $\left(E_{7}^{1}\right)$, hydride transfer potentials $\left(E_{7}\left(\mathrm{H}^{-}\right)\right)$, pK $K_{\mathrm{a}}$ of semiquinones $\left(\mathrm{p} K_{\mathrm{a}}(\mathrm{QH} \cdot)\right)$, and van der Waals volumes (VdWvol).

The values of $E_{7}^{1}, E_{7}\left(\mathrm{H}^{-}\right)$, and $\mathrm{p} K_{\mathrm{a}}(\mathrm{QH})$ are taken from Wardman (1989) and Čènas et al. (2004).

\begin{tabular}{|c|c|c|c|c|c|c|c|}
\hline No. Compound & $\begin{array}{l}k_{\text {cat }} \\
\left(\mathrm{s}^{-1}\right)\end{array}$ & $\begin{array}{l}k_{\mathrm{cat}} / K_{\mathrm{m}} \\
\left(\mathrm{M}^{-1} \mathrm{~s}^{-1}\right)\end{array}$ & $\begin{array}{l}K_{\mathrm{iq}} \\
(\mu \mathrm{M})\end{array}$ & $\begin{array}{l}E_{7}^{1} \\
(\mathrm{~V})\end{array}$ & $\begin{array}{c}E_{7}\left(\mathrm{H}^{-}\right) \\
(\mathrm{V})\end{array}$ & $\mathrm{p} K_{\mathrm{a}}(\mathrm{QH} \cdot)$ & $\begin{array}{l}\text { VdWvol } \\
\left(\AA^{3}\right)\end{array}$ \\
\hline 1. 2-Methyl-1,4-benzoquinone ${ }^{a}$ & $30.3 \pm 3.9$ & $9.3 \pm 1.8 \times 10^{6}$ & 80.0 & 0.01 & 0.120 & 4.45 & 142.5 \\
\hline 2. $\mathrm{AZQ}^{\mathrm{a}}$ & $29.2 \pm 1.2$ & $1.4 \pm 0.1 \times 10^{6}$ & & -0.07 & -0.046 & 6.30 & 360.6 \\
\hline 3. 2,6-Dimethyl-1,4-benzoquinone ${ }^{b}$ & $26.9 \pm 1.9$ & $1.1 \pm 0.2 \times 10^{7}$ & 56.0 & -0.08 & 0.058 & 4.75 & 160.6 \\
\hline 4. 5-Hydroxy-1,4-naphthoquinone ${ }^{b}$ & $16.0 \pm 2.0$ & $1.4 \pm 0.1 \times 10^{7}$ & 3.0 & -0.09 & -0.060 & 3.65 & 179.7 \\
\hline 5. Methylene blue ${ }^{a}$ & $25.6 \pm 0.4$ & $1.3 \pm 0.1 \times 10^{6}$ & & -0.10 & 0.00 & & 297.6 \\
\hline 6. 5,8-Dihydroxy-1,4-naphthoquinone ${ }^{\text {b }}$ & $25.0 \pm 3.0$ & $5.0 \pm 0.7 \times 10^{7}$ & 4.0 & -0.11 & -0.084 & 2.80 & 192.3 \\
\hline 7. 9,10-Phenanthrene quinone ${ }^{\mathrm{a}}$ & $30.0 \pm 3.0$ & $1.2 \pm 0.1 \times 10^{7}$ & 25.0 & -0.12 & -0.034 & & 218.3 \\
\hline 8. 1,4-Naphthoquinone ${ }^{\mathrm{a}}$ & $34.1 \pm 2.9$ & $1.8 \pm 0.3 \times 10^{7}$ & 44.4 & -0.15 & -0.029 & 4.10 & 168.1 \\
\hline 9. 2,3-Diglutathionyl-1,4-naphthoquinone ${ }^{\mathrm{a}}$ & $7.2 \pm 1.4$ & $1.2 \pm 0.1 \times 10^{5}$ & & -0.15 & $-0.029^{c}$ & & 684.0 \\
\hline 10. 2-Methyl-5-hydroxy-1,4-naphthoquinone ${ }^{a}$ & $19.6 \pm 2.0$ & $9.6 \pm 0.3 \times 10^{6}$ & 46.0 & -0.16 & & & 199.6 \\
\hline $\begin{array}{l}\text { 11. 2-Methyl-3-glutathionyl-5-hydroxy-1,4- } \\
\text { naphthoquinone }^{\mathrm{a}}\end{array}$ & $32.1 \pm 2.5$ & $2.0 \pm 0.5 \times 10^{6}$ & 115 & -0.16 & & & 455.6 \\
\hline 12. 2,3,5-Trimethyl-1,4-benzoquinone $\mathrm{e}^{\mathrm{b}}$ & $32.6 \pm 2.0$ & $8.8 \pm 0.5 \times 10^{6}$ & $>100$ & -0.17 & 0.00 & 5.00 & 178.5 \\
\hline 13. 2-Methyl-1,4-naphthoquinone ${ }^{a}$ & $30.7 \pm 3.9$ & $1.9 \pm 0.4 \times 10^{7}$ & 19.6 & -0.20 & -0.114 & 4.50 & 187.2 \\
\hline 14. 9,10-Anthraquinone-2,6-disulfonate ${ }^{\mathrm{a}}$ & $11.1 \pm 0.1$ & $1.2 \pm 0.1 \times 10^{5}$ & & -0.25 & -0.21 & 3.00 & 314.5 \\
\hline 15. Tetramethyl-1,4-benzoquinone ${ }^{b}$ & $22.0 \pm 3.0$ & $5.0 \pm 1.5 \times 10^{5}$ & 30 & -0.26 & -0.086 & 5.10 & 197.5 \\
\hline 16. Riboflavin ${ }^{\mathrm{a}}$ & $4.4 \pm 0.05$ & $2.6 \pm 0.1 \times 10^{4}$ & & -0.318 & -0.21 & 8.50 & 422.7 \\
\hline 17. 1,8-Dihydroxy-9,10-anthraquinone ${ }^{\mathrm{a}}$ & $4.0 \pm 0.1$ & $2.0 \pm 0.1 \times 10^{5}$ & & -0.325 & & 3.95 & 245.5 \\
\hline 18. $\mathrm{BZQ}^{\mathrm{a}}$ & $0.4 \pm 0.05$ & $1.8 \pm 0.1 \times 10^{3}$ & & -0.385 & -0.32 & & 308.5 \\
\hline 19. 1-Hydroxy-9,10-anthraquinone ${ }^{\mathrm{a}}$ & $4.7 \pm 0.2$ & $1.1 \pm 0.1 \times 10^{5}$ & & -0.385 & & 4.60 & 231.5 \\
\hline 20. 2-Hydroxy-1,4-naphthoquinone ${ }^{\mathrm{a}}$ & $1.1 \pm 0.1$ & $9.2 \pm 1.2 \times 10^{4}$ & & -0.41 & -0.20 & 4.70 & 179.7 \\
\hline 21. 2-Methyl-3-hydroxy-1,4-naphthoquinone ${ }^{a}$ & $1.1 \pm 0.3$ & $2.5 \pm 0.5 \times 10^{4}$ & & -0.46 & -0.24 & & 199.6 \\
\hline
\end{tabular}

${ }^{a}$ Kinetic parameters and $K_{\mathrm{iq}}$ were determined at fixed NADPH concentration $(150 \mu \mathrm{M})$; ${ }^{\mathrm{b}} k_{\text {cat }}$ determined at saturating NADPH concentration, $K_{\text {is }}$ determined by extrapolation to $[\mathrm{NADPH}]=0$; 'Assumed to be the same as for 1,4-naphthoquinone.

$\left(\mathrm{r}^{2}=0.6233, \mathrm{~F}(1,19)=31.17\right.$, not shown $)$, as well as the parabolic (second order) relationship $\left(\mathrm{r}^{2}=0.6352\right.$, $\mathrm{F}(2,18)=15.60$, Fig. 2A). The omission of bulky glutathione conjugates (compounds 9,11 (Table 1)) slightly improved the regressions, giving $\mathrm{r}^{2}=0.6777$, $\mathrm{F}(1,17)=35.60$ (linear), and $\mathrm{r}^{2}=0.7015, \mathrm{~F}(2,16)=18.86$ (parabolic). The data of Fig. 2B show that the reactivity of several quinones with similar $E^{1}{ }_{7}$ values decreases with an increase in their VdWvol. Using VdWvol of quinones as an additional parameter, the second order regression was markedly improved $\left(r^{2}=0.8538, F(3,17)=31.50\right)$ : $\log k_{\mathrm{cat}} / K_{\mathrm{m}}=(8.00 \pm 0.38)-(1.35 \pm 3.57) E^{1}{ }_{7}-(18.49 \pm 7.34)$ $\left(E_{7}^{1}\right)^{2}-(0.45 \pm 0.09) \times 10^{-2}$ VdWvol, $(\mathrm{n}=21)$

The introduction of $\mathrm{p} K_{\mathrm{a}}(\mathrm{QH})$ (Table 1) as a third variable did not improve the regression significantly $\left(\mathrm{r}^{2}=0.9103, \mathrm{~F}(4,9)=19.04\right)$ :

$\log k_{\mathrm{cat}} / K_{\mathrm{m}}=(7.94 \pm 0.43)-(2.50 \pm 3.02) E^{1}{ }_{7}-(19.09 \pm 6.96)$

$\left(E_{7}^{1}\right)^{2}-(0.69 \pm 0.13) \times 10^{-2} \mathrm{VdWvol}+(0.07 \pm 0.08)$

$\mathrm{p} K_{\mathrm{a}}(\mathrm{QH}),(\mathrm{n}=14)$ 

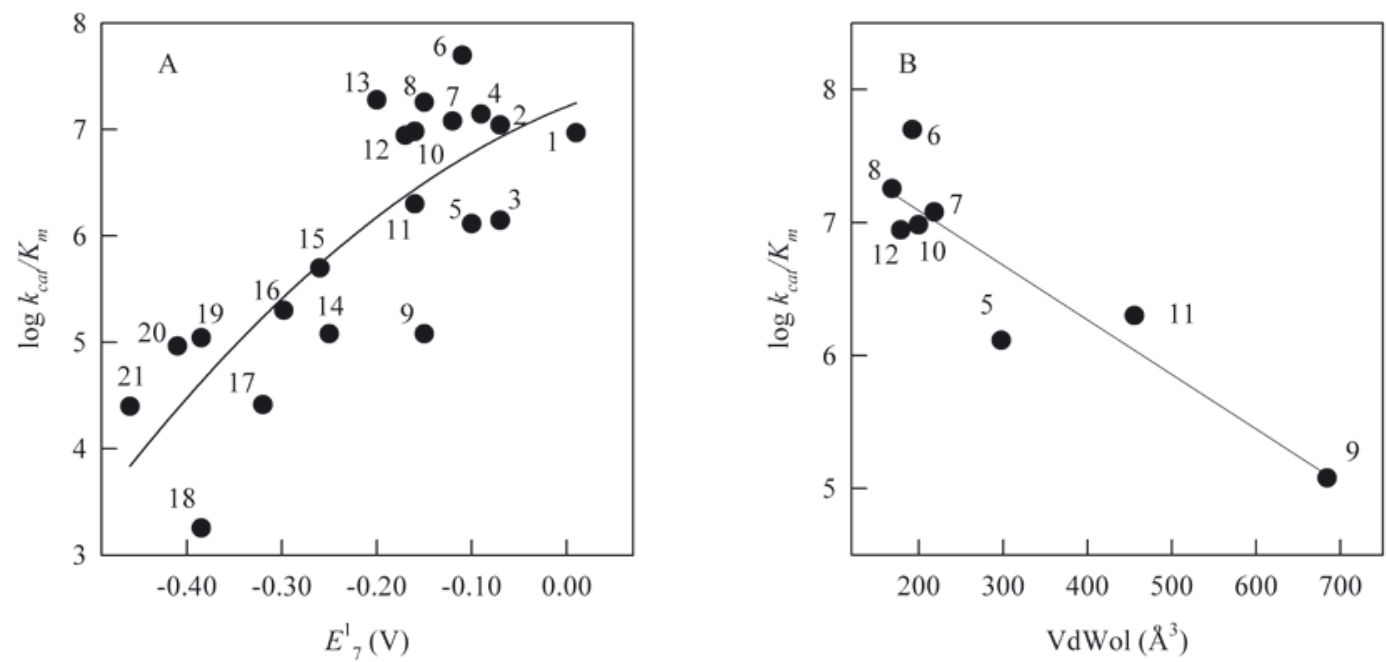

Figure 2. Dependence of the reactivity of PETNR on the electron-accepting potency and steric parameters of quinones.

A. Dependence of $k_{\text {cat }} / K_{\mathrm{m}}$ of quinones on their single-electron reduction potentials $\left(E_{7}^{1}\right)$. B. Dependence of $k_{\text {cat }} / K_{\mathrm{m}}$ of quinones on their Van der Waals volume (VdWvol). The numbers of compounds are taken from Table 1.

giving an uncertain dependence of quinone reactivity on the proton-accepting potency of their radicals (Eqn. 5). We failed to improve the regressions by the introduction of $(\mathrm{VdWvol})^{2}$ as an additional variable.

Alternatively, analyzing quinone reactivity in terms of a single-step hydride transfer (Eqn. 2), we found that their $\log k_{\text {cat }} / K_{\mathrm{m}}$ increased with an increase in $E_{7}\left(\mathrm{H}^{-}\right)$(Table 1), although the regressions were poorly expressed $\left(\mathrm{r}^{2}=0.5897, \mathrm{~F}(1,15)=21.51\right.$ (linear, not shown), and $\mathrm{r}^{2}=0.6979, \mathrm{~F}(2.14)=16.04$ (parabolic, Fig. 3A)). Using VdWol of quinones as an additional parameter, the regression was considerably improved $\left(\mathrm{r}^{2}=0.8621, \mathrm{~F}(3,13)=27.09\right)$ :

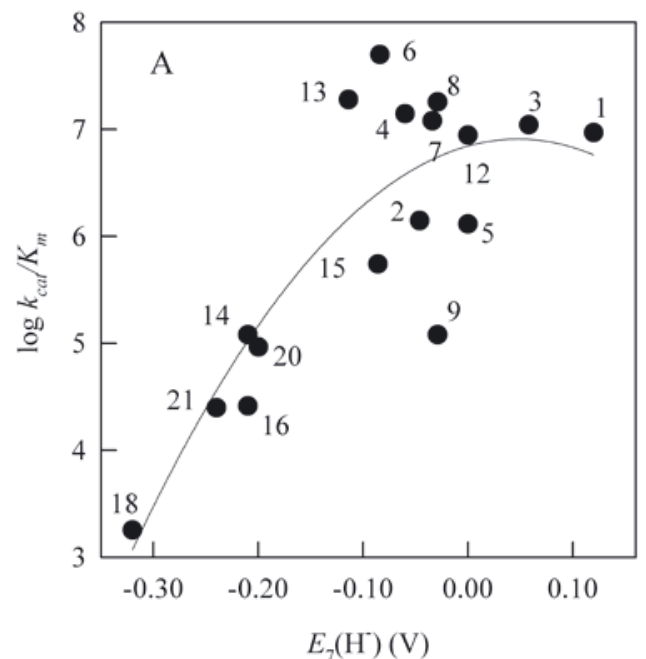

$\log k_{\mathrm{cat}} / K_{\mathrm{m}}=(7.81 \pm 0.30)+(1.03 \pm 2.23) E_{7}\left(\mathrm{H}^{-}\right)-$ $(32.66 \pm 8.96)\left(E_{7}\left(\mathrm{H}^{-}\right)\right)^{2}-(0.40 \pm 0.10) \times 10^{-2} \mathrm{VdWvol}$ $(\mathrm{n}=17)$.

The obtained structure-activity relationships (Eqns. (4-6)) are equally well consistent with both three-step and single-step hydride transfer (Eqns. 1, $2)$, demonstrating similar negative coefficients $\Delta \log$ $\left(k_{\mathrm{cat}} / \mathrm{K}_{\mathrm{m}}\right) / \Delta \mathrm{VdWvol}$ in both cases. In order to define the reaction mechanism, we studied the $\mathrm{pH}$-dependence of the reactivity of riboflavin and tetramethyl1,4-benzoquinone (Fig. 3B). This approach, which has been used in the studies of E. cloacae NR (Nivinskas et al., 2002), is based on the pH-independent

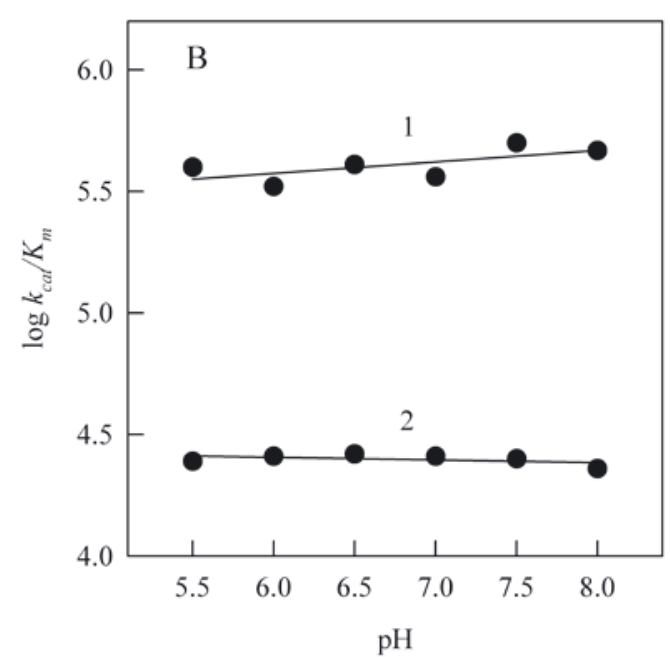

Figure 3. Dependence of the reactivity of PETNR on the hydride-accepting potency of quinones and on $\mathrm{pH}$. A. Dependence of $k_{\text {cat }} / K_{\mathrm{m}}$ of quinones on their hydride-transfer potential $\left(E_{7}\left(\mathrm{H}^{-}\right)\right)$. The numbers of compounds are taken from Table 1. B. $\mathrm{pH}$ dependence of $k_{\mathrm{cat}} / K_{\mathrm{m}}$ of tetramethyl-1,4-benzoquinone (1) and riboflavin (2). 
single-electron reduction potential of tetramethyl-1,4benzoquinone at $\mathrm{pH} 5.5-8.0\left(\mathrm{pK}_{\mathrm{a}}(\mathrm{QH} \cdot)=4.6\right.$, Table 1$)$, and the negative dependence of $E^{1}$ of riboflavin on $\mathrm{pH}$ with $\Delta E^{1} / \Delta \mathrm{pH}=-0.059 \mathrm{~V}\left(\mathrm{pK}_{\mathrm{a}}(\mathrm{QH} \cdot)=8.8\right.$, Table 1$)$. In the case of a three-step hydride transfer with the partly rate-limiting first electron transfer (Eqn. 1), an increase in $\mathrm{pH}$ should relatively decrease the reactivity of riboflavin with respect to the reactivity of tetramethyl-1,4-benzoquinone. However, the $\log k_{\text {cat }}$ ' $K_{\mathrm{m}}$ values of both compounds were $\mathrm{pH}$-independent (Fig. 3B). This is consistent with a single-step hydride transfer (Eqn. 2), because the $\mathrm{pH}$-dependence of hydride-transfer potentials of both compounds is the same, $\Delta E\left(\mathrm{H}^{-}\right) / \Delta \mathrm{pH}=-0.030 \mathrm{~V}$.

\section{DISCUSSION}

Our data show that the reactivity of quinones towards two-electron transferring PETNR is relatively insensitive to their structural peculiarities, and depends mainly on the energetics of charge transfer (Figs. 2A, 3A, Eqns. 4-6). In this aspect, PETNR differs from NQO1, whose reactivity is much more sensitive to the steric effects of quinones with the coefficients $\Delta \log \left(k_{\text {cat }} / K_{\mathrm{m}}\right) / \Delta \mathrm{VdWvol}=-1.46-1.69 \times 10^{-2}$ (Anusevičius et al., 2002; Čènas et al., 2004), which distort the reactivity dependence on the quinone reduction potential. PETNR also differs from E. cloacae $\mathrm{NR}$, which is relatively insensitive to the VdWvol of quinones, but shows a pronounced specificity towards 2-hydroxy-1,4-naphthoquinone structure (Nivinskas et al., 2002). A similar parabolic $\log k_{\text {cat }} /$ $K_{\mathrm{m}}$ vs. $E_{7}^{1}$ dependence for a limited number of quinones has been demonstrated in their two-electron reduction by Clostridium kluyveri diaphorase (Čènas et al., 1987). Thus, our data provide further evidence that in certain cases the two-electron (hydride) reduction of quinones by flavoenzymes may not be significantly influenced by the specific interactions, similar to their single-electron reduction by flavoenzymes dehydrogenases-electrontransferases. Thus, the flavin semiquinone instability may be a sufficient factor for the two-electron (hydride) reduction of quinones. Although the reduction of quinones by PETNR is interesting mainly as a model reaction, it has been recently shown that a member of the OYE family is the main enzyme in Trypanosoma cruzi responsible for the NADPH-dependent bioreductive activation of trypanocidal quinones and aromatic nitrocompounds (Kubata et al., 2002).

It is of certain interest to compare the 'intrinsic' reactivities of two-electron transferring flavoenzymes, i.e., their $k_{\mathrm{cat}} / K_{\mathrm{m}}$ of quinone reduction at $\Delta E_{7}\left(\mathrm{H}^{-}\right)$about 0 . Because E. cloacae NR contains anionic $\mathrm{FMNH}^{-}$at $\mathrm{pH} 7.0$, its $E_{7}\left(\mathrm{H}^{-}\right)=E_{\mathrm{m}, 7}=-0.190 \mathrm{~V}$ (Koder et al., 2002). X-Ray studies also suggest the presence of anionic reduced flavins in NQO1 and PETNR (Li et al., 1995; Barna et al., 2001). Thus, their $E_{7}\left(\mathrm{H}^{-}\right)$may be equal to or below their $E_{\mathrm{m}, 7}$ (Eqn. 3, i.e., $-0.159 \mathrm{~V}$ (NQO1, Tedeschi et al., 1995), and -0.267 V (PETNR, Khan et al., 2004). At $\Delta E_{7}\left(\mathrm{H}^{-}\right) \sim 0$, the quinone reduction rate constant by NQO1 may reach $10^{7} \mathrm{M}^{-1} \mathrm{~s}^{-1}$ (Anusevičius et al., 2002). In E. cloacae NR the rate constant varies between about $10^{7} \mathrm{M}^{-1} \mathrm{~s}^{-1}$ (2-hydroxy-1,4-naphthoquinone) and about $10^{5} \mathrm{M}^{-}$ ${ }^{1} \mathrm{~s}^{-1}$ (other compounds) (Nivinskas et al., 2002). In contrast, the 'intrinsic' reactivity of PETNR is lower, being close to $10^{4} \mathrm{M}^{-1} \mathrm{~s}^{-1}$ (Table 1, Fig. 3A). This may point to a less efficient electronic interaction between quinones and $\mathrm{FMNH}^{-}$isoalloxazine ring in PETNR. Indeed, the binding of quinones in the active center of NQO1 involves their $\pi-\pi$ stacking with the flavin isoalloxazine ring, with the displacement of the aromatic residues of Tyr-128' and Phe-178', the latter stacking behind the quinone ring (Li et al., 1995). The binding of benzoate to E. cloacae NR involves some displacement of Phe-124 and Tyr-123, however, these residues do not stack with benzoate (Haynes et al., 2002). In contrast, the binding of steroid or nitroaromatic ligands to PETNR involves only small perturbations of Tyr-351, Tyr-186 and/or Trp-102 (Barna et al., 2001; Khan et al., 2002; 2004), without any stacking interactions. These data enabled us to conclude that the active center of PETNR is flexible, and is able to accommodate large ligands without significant aminoacid displacements. This property is most probably responsible for the less efficient electronic interaction between quinones and $\mathrm{FMNH}^{-}$ in PETNR, and, in parallel, for the absence of pronounced discrimination of bulky oxidants.

\section{Acknowledgements}

This work was supported in part by the Agency for International Science and Technology Development Programmes in Lithuania (COST B22).

\section{REFERENCES}

Anusevičius Ž, Martinez-Julvez M, Genzor CG, Nivinskas H, Gomez-Moreno C, Čènas N (1997) Electron transfer reactions of Anabaena PCC 7119 ferredoxin:NADP ${ }^{+}$ reductase with nonphysiological oxidants. Biochim Biophys Acta 1320: 247-255.

Anusevičius Ž, Šarlauskas J, Čènas N (2002) Two-electron reduction of quinones by rat liver $\mathrm{NAD}(\mathrm{P}) \mathrm{H}$ : quinone oxidoreductase: quantitative structure-activity relationships. Arch Biochem Biophys 404: 254-262.

Barna TM, Khan H, Bruce NC, Barsukov I, Scrutton NS, Moody PCE (2001) Crystal structure of pentaerythritol tetranitrate reductase: "flipped" binding geometries for steroid substrates in different redox states of the enzyme. J Mol Biol 310: 433-447.

Basran J, Harris RJ, Sutcliffe MJ, Scrutton NS (2003) H-tunneling in the multiple $\mathrm{H}$-transfers of the catalytic cycle 
of morphinone reductase and in the reductive half-reaction of the homologous pentaerythritol tetranitrate reductase. J Biol Chem 278: 43973-43982.

Binks PR, French CE, Nicklin S, Bruce NC (1996) Degradation of pentaerythritol tetranitrate by Enterobacter cloacae PB2. Appl Environ Microbiol 62: 1214-1219.

Carlson BW, Miller LL (1985) Mechanism of the oxidation of NADH by quinones. Energetics of one-electron and hydride routes. I Am Chem Soc 107: 479-485.

Čènas NK, Vienožinskis JV, Kulys JJ (1987) Kinetic regularities of $\mathrm{Cl}$. kluyveri diaphorase. Biokhimiya 52: 91-96 (in Russian)

Čènas N, Anusevičius Ž, Bironaitė D, Bachmanova GI, Archakov AI, Ollinger K (1994) The electron transfer reactions of NADPH:cytochrome $\mathrm{P} 450$ reductase with nonphysiological oxidants. Arch Biochem Biophys 315: 400-406.

Čènas N, Anusevičius Ž, Nivinskas H, Misevičienė L, Šarlauskas J (2004) Structure-activity relationships in two-electron reduction of quinones. Methods Enzymol 382B: 258-277.

Chou F, Khan AH, Driscoll JS (1976) Potential central nervous system antitumor agents. Aziridinylbenzoquinones. 2. J Med Chem 19: 1302-1308.

French CE, Nicklin S, Bruce N (1996) Sequence and properties of pentaerythritol tetranitrate reductase from Enterobacter cloacae PB2. I Bacteriol 178: 6623-6627.

French CE, Nicklin S, Bruce N (1998) Aerobic degradation of 2,4,6-trinitrotoluene by Enterobacter cloacae PB2 and by pentaerythritol tetranitrate reductase. Appl Environ Microbiol 64: 2864-2868.

Fukuzumi S, Ishikawa M, Tanaka T (1989) Acid-catalysed reduction of $p$-benzoquinone derivatives by an NADH analoque, 9,10-dihydro-10-methylacridine. The energetic comparison of one-electron vs. two-electron pathways. J Chem Soc Perkin Trans 2: 1811-1816.

Haynes CA, Koder RL, Miller A-F, Rodgers DW (2002) Structures of nitroreductase in three states. Effects of inhibitor binding and reduction. J Biol Chem 277: 11513-11520.

Iyanagi T (1990) On the mechanism of one-electron and two-electron reduction of quinones by microsomal flavin enzymes - the kinetic analysis between cytochrome-B5 and menadione. Free Radic Res Commun 8: 259-268.
Khan H, Harris RJ, Barna T, Craig DH, Bruce NC, Munro AW, Moody PCE, Scrutton NS (2002) Kinetic and structure basis of reactivity of pentaerythritol tetranitrate reductase with NADPH, 2-cyclohexenone, nitroesters and nitroaromatic explosives. J Biol Chem 277: 21906-21912.

Khan H, Barna T, Harris RJ, Bruce NC, Barsukov I, Munro AW, Moody PCE, Scrutton NS (2004) Atomic resolution structures and solution behavior of enzyme-substrate complexes of Enterobacter cloacae PB2 pentaerythritol tetranitrate reductase. J Biol Chem 279: 30563-30572.

Koder RL, Haynes CA, Rodgers ME, Rodgers DW, Miller A-F (2002) Flavin thermodynamics explain the oxygen insensitivity of enteric nitroreductases. Biochemistry 41: 14197-14205.

Kubata BK, Kabututu Z, Nozaki T, Munday CJ, Fukuzumi S, Ohkubo K, Lazarus M, Lazarus M, Maruyama T, Martin SK, Duszenko M, Urade Y (2002) A key role for old yellow enzyme in the metabolism of drugs by Trypanosome cruzi. J Exp Med 196: 1241-1251.

Li R, Bianchet MA, Talalay P, Amzel M (1995) The threedimentional structure of $\mathrm{NADP}(\mathrm{H})$ : quinone reductase, a flavoprotein involved in cancer chemoprotection and chemotherapy: mechanism of the two-electron reduction. Proc Natl Acad Sci USA 92: 8846-8850.

Marcus RA, Sutin N (1985) Electron transfers in chemistry and biology. Biochim Biophys Acta 811: 265-322.

Massey V, Schopfer LM (1986) Reactivity of old yellow enzyme with alpha-NADPH and other pyridine nucleotides. J Biol Chem 261: 1215-1222.

Nivinskas H, Staškevičienė S, Šarlauskas J, Koder RL, Miller A-F, Čènas N (2002) Two-electron reduction of quinones by Enterobacter cloacae $\mathrm{NAD}(\mathrm{P}) \mathrm{H}$ : nitroreductase: quantitative structure-activity relationships. Arch Biochem Biophys 403: 249-258.

O'Brien PJ (1991) Molecular mechanisms of quinone cytotoxicity. Chem Biol Interact 80: 1-41.

Tedeschi G, Chen S, Massey V (1995) DT-diaphorase. Redox potential, steady-state, and rapid reaction studies. J Biol Chem 270: 1198-1204.

Wardman P (1989) Reduction potentials of one-electron couples involving free radicals in aqueous solutions. $J$ Phys Chem Ref Data 18: 1637-1755. 